\title{
Research Priorities and Indicators for Lifestyle Programs to Address Cardiometabolic Conditions
}

Paula Brauer ( $\sim$ phcnutr@uoguelph.ca )

University of Guelph https://orcid.org/0000-0001-9822-1992

\section{Sophie Desroches}

Université Laval: Universite Laval

\section{Rupinder Dhaliwal}

Metabolic Syndrome Canada

\section{Airu Li}

University of Guelph

\section{Yiran Wang}

University of Toronto Dalla Lana School of Public Health

\section{Annalijn Conklin}

University of British Columbia

\section{Doug Klein}

University of Alberta

Jean-Philippe Drouin-Chartier

Université Laval: Universite Laval

Julie Robitaille

Université Laval: Universite Laval

Justine Horne

Université Laval: Universite Laval

\section{Monia Ponta}

University Health Network

\section{Rachel Burns}

Carleton University

\section{Scott Harding}

Memorial University of Newfoundland

\section{Zeinab Hosseini}

University of Saskatchewan College of Kinesiology

\section{Research}


Keywords: Delphi, expert consensus, pre-diabetes, metabolic syndrome, cardiometabolic disease, implementation science, primary health care, public health, lifestyle interventions, research priority

Posted Date: December 1st, 2020

DOI: https://doi.org/10.21203/rs.3.rs-115986/v1

License: (1) This work is licensed under a Creative Commons Attribution 4.0 International License. Read Full License 


\section{Abstract}

Background: Cardiometabolic conditions are a major and growing health burden in many countries. At least one-third of middle-aged adults with overweight and obesity develop various combinations of type 2 diabetes, hypertension, dyslipidemia, and other cardiometabolic conditions. Currently, all relevant clinical and community guidelines recommend lifestyle (e.g. diet and physical activity) interventions, yet current evidence suggests limited and variable uptake by either primary care or public health services. New implementation research in lifestyle interventions is needed in multiple jurisdictions. As part of this effort, some agreement within the research community on priorities and core measures and indicators across studies would improve comparability and drive progress. Members of a new volunteer network undertook a first Delphi process to determine initial consensus.

Methods: Network members were invited by email to participate and completed two rounds of a modified Delphi process delivered through online questionnaire and teleconferences. Results were sent back to participants at the end of each round of the survey. High priority with consensus was defined as the median and $25-75 \%$ ile range within the 7 to 9 range on a 9 -point scale.

Results: Fifty-three people were invited and provided with a link to the first questionnaire. Twenty-five (47\%) and 18 (34\%) participants completed the round 1 and round 2 surveys, respectively. Of 22 possible research priorities, four were rated high priority with consensus, including: evaluating the efficacy and effectiveness of interventions in place, improving existing interventions for sustainability, and clinical and public health research to advance existing knowledge to develop new capacities. Of the 93 measures and indicators proposed, 15 achieved consensus with an additional nine measures having high medians, but greater variance.

Conclusions: This first effort suggests a wide range of research priorities within the group, but also broad agreement on a few core implementation research priorities. There is currently limited agreement on core indicators/measures for implementation studies and additional work is needed. The results provide a starting point for further development of common measures for implementation research in lifestyle interventions for cardiometabolic conditions.

\section{Contribution To The Literature}

- Researchers agree that new public health and clinical implementation studies are needed to address the high prevalence of cardiometabolic conditions.

- Delphi study in a newly formed research network for lifestyle approaches identified highest research priorities and possible core measures for such studies.

- The need for inter-disciplinary and inter-sectoral approaches was highlighted by participants.

\section{Background}


Cardiometabolic conditions and diseases are a major and growing health burden in many countries, as obesity continues to increase worldwide (1). Excess body weight is associated with heterogenous metabolic effects and health risk implications have been variously described by different research groups (2). Cardiovascular disease (CVD) remains a prominent clinical disease risk. Adverse metabolic effects of excess body weight become more prominent in middle age, with about $40 \%$ of adults older than 60 years having metabolic syndrome (3), characterized by three or more indicators including higher waist circumference, higher blood pressure, dyslipidemia characterized by low high-density lipoprotein and elevated triglyceride levels, and elevated glucose levels (4). According to the Framingham Risk Score, one of the current established clinical tools for estimating 10-year CVD risk (5), 29\% of Canadians 20-79 were at intermediate or high risk (6).

Significant progress has been made in understanding the pathophysiological basis of these conditions and numerous clinical trials of behaviour change and medications have been conducted. Although the importance of diet and exercise in moderating these conditions was recognized from the early CVD trials, such as the Multiple Risk Factor Intervention Trial (MRFIT) in the mid-1970s (7), current health care practice tends to focus on the provision of medications over formal behavioural interventions (8). While MRFIT focused on the treatment of high cholesterol levels, hypertension, and smoking (7), obesity and diabetes have emerged in the years since, as important conditions that also need to be addressed (5).

Currently, all relevant practice guidelines suggest combining lifestyle interventions with medical treatment to prevent and treat cardiometabolic conditions $(5,9-11)$. However, discrepancies exist between recommended interventions and actual health care practice, with limited and variable uptake by either primary care or public health (8). Why is uptake poor? Among the many barriers, high prevalence of cardiometabolic conditions, competing priorities, limited evidence for effectiveness in different contexts (rural and remote; population subgroups), lack of common metrics across studies, and lack of capacity and resources have been cited (12).

The need for implementation research in the areas of health behaviour and lifestyle has been recognized $(13,14)$. Many of the resources for lifestyle change in communities, such as recreation centres and parks, already exist but have not necessarily been focused on addressing cardiometabolic conditions.

Determining the most effective and efficient strategies to address cardiometabolic conditions and diseases is not straight forward. To encourage more implementation research, individual researchers and teams need to come together, develop proposals, obtain funding and test various approaches. A wide range of academic and professional expertise is needed in areas such as nutrition, kinesiology, psychology, behaviour change, social work, family medicine, public health medicine, nursing, epidemiology, political science, policy analysis, digital communications, project management, and health economics to find the best mix of services for different health system contexts.

Such implementation studies need to address key questions, using measures and outcomes that will be valid and comparable over time. To achieve this goal, the objective of this preliminary consensus study was to identify initial areas and degree of consensus on potential research priorities and core measures 
for lifestyle implementation studies, building on previous research and literature reviews which collectively have indicated little consistency (e.g., Li, A. PROSPERO CRD42018075697). We employed Delphi techniques to achieve this objective. Originally developed by the Research and Development (RAND) corporation (15), the method has evolved over time, with numerous variations (16). Online survey methods and digital technology for discussions offer new opportunities to engage diverse participants. The literature on previous research prioritization $(17,18)$ and indicator efforts was reviewed, as multiple groups have been undertaking such efforts, using a range of approaches, from consensus by an invited group of experts to formal Delphi processes to identify both areas of agreement and divergent views.

\section{Methods}

\section{Study Design}

A two-round modified virtual Delphi process was planned and conducted in Feb-April 2020. We followed the Recommendations for the Conducting and Reporting of Delphi Studies (CREDES). See Additional file 1: Appendix A.

\section{Participant recruitment}

As a first step, funding was obtained to initiate a new network of researchers to promote the development of new research proposals and identify parameters for potential implementation proposals (see Figure 1). Potentially interested researchers and implementation experts from Canada, the United States, United Kingdom and Australia were identified from personal contacts and from discussion at two conferences in 2019: Diabetes Canada and North American Primary Care Research Group. In addition, all researchers active in Canada who had published on primary care and/or lifestyle interventions in diabetes, prediabetes and metabolic syndrome over the past 10 years were identified through PubMed and CINAHL and contacted by email for possible interest in the network. Two teleconferences and a webinar on knowledge translation had been completed prior to initiating the Delphi process. Invitation emails were sent to 53 network members with a link to the survey and an attached document describing the purpose and process, as well as shared access (through Dropbox) to six key background papers (18-23). They were also encouraged to send an invitation to interested others.

\section{Questionnaire Development}

\section{Evaluation Criteria and Research Priorities}

A preliminary list of research priorities was generated through feedback from network members from the first two teleconferences $(n=53)$. The list was highly diverse and included a mixture of specific and general topics, reflecting the many ways research can be described. The literature was therefore searched for possibly relevant implementation research frameworks. The work of the Child Health and Nutrition Research Initiative (CHNRI) was notable as they had used systematic and transparent methods to set child-focused health systems research priorities in low-income and middle-income countries (24). 
Multiple health research prioritization exercises had been undertaken over several years using CHNRI methods and two innovations were adapted to the present project. The first was an explicit list of prioritysetting criteria that might apply to judgments of different stakeholders in a research priority-setting context. These 20 evaluation criteria were rated for relevance to our topic area (23). The second innovation was the use of the 4D framework for describing research focus ("description", "delivery", "development" and "discovery" research), which we adapted to describe 22 specific research areas for assessment (23). See Additional File 1: Appendix B for 20 options related to Evaluation Criteria and 22 research areas included under Research Priorities.

\section{Indicators and Measures}

Measures from two different consensus processes addressing obesity management were categorized, combined and adapted by one researcher (PB) to create an initial list. Some measures were identified by both groups, but many were not. The Accumulating Data to Optimally Predict Obesity Treatment (ADOPT) is a US-based effort to better understand and deliver tailored obesity treatments, based on behavioural, biological, environmental, and psycho-social domains. Part of this work involved the development of a Core List of Constructs and Measures, an initial list of high-priority constructs based on the current state of science (21). The OBEsity Diverse Interventions Sharing group (OBEDIS) developed a set of European guidelines for a minimal set of variables to include in future clinical trials on obesity, regardless of the specific endpoints (19). In addition, other possible measures were identified from previous implementation study guides $(20,22)$. The final seven categories were:

- Demographic/Environment/Context (15 indicators/measures)

- Diet and Physical Activity (8 indicators/measures)

- Formative and Process Measures (6 indicators/measures)

- Psycho-social Constructs (21 indicators/measures)

- Body Composition and Energy Estimation (6 indicators/measures)

- Biological/Clinical/History measures (33 indicators/measures)

- Social Environment (4 indicators/measures)

The finalized online Delphi survey was divided into three sections - Evaluation Criteria, Research Priorities, and Measures/Constructs/Outcomes. Each statement was rated on a 9-point scale, which ranged from not relevant/ not priority/not core (1-3), to uncertain/ equivocal (4-6), to highly relevant/priority/core (7-9). The survey avoided making any forced responses and provided forwardbackward buttons. Additional suggestions and comments were requested at the end of each section. The survey was reviewed and pilot-tested by the research group. The round 1 and round 2 surveys were very similar, with 132 and 135 statements, respectively. In particular based on feedback from round 1, in round 2, two indicators were added to the Demographic/Environment/Context (i.e. marital status and material hardship (e.g. difficulty paying bills, rent etc.) and one indicator was added to Diet and Physical Activity 
(i.e. type / extent of food processing as indicator of diet quality). See the Additional File 1: Appendix B for the Final Delphi Questionnaire.

\section{Data collection}

Each round of the Delphi process was delivered as a self-administered survey (developed and delivered through Qualtrics ${ }^{\circledR}$ ) and debriefing virtual meetings (delivered through ZOOM). Six relevant background papers were made available to all participants by Dropbox Sharing feature (18-23). For round 1, participants had about 2 weeks to complete the survey (Feb 25 - Mar 12,2020). Before round 2, they received an Excel summary listing each statement, the group results (median and 25-75\%ile), and their own answers. Two virtual meetings were conducted to allow for differences in participant schedules. Both meetings had the same format of reviewing the overall results and most contentious statements, as well as a general discussion of the process. Meeting notes were reviewed by the research team and sent to participants after each meeting. For round 2, the survey was deployed with a 2-week turn-around (Mar 28 - Apr 12, 2020) and results were again sent back to participants. A final online conference meeting was held in April 2020 to review results and discuss next steps for the development of the network.

\section{Analysis}

Initial review of group results after round 1 indicated that all but one statement (Evaluation Criteria: Likelihood of generating patents/lucrative products) was at least partially supported, so scores were highly left skewed. Despite encouragement to use the full scoring range, scores were still highly skewed after round 2. To report results, we therefore used the most strict definition of strong agreement, as described by the original developers (15), which required that all three indicators (median, $25^{\text {th }}$ and $75^{\text {th }}$ percentile) fell within the 1-3 or 7-9 range. A second set of statements had the median and $75 \%$ ile fall within $7-9$ range, but the $25 \%$ ile indicated more variable scoring. These statements achieved weaker agreement. The third group of uncertain statements had lower medians and diverse ranges.

\section{Results}

\section{Participation}

A total of 53 researchers from Canada $(n=47)$, US $(n=3), U K(n=1)$ and Australia $(n=2)$ expressed interest in the network and 50 of them were interested in participating in the Delphi process. Only one member of the research team (PB) did not complete the Delphi questionnaire. Of the 53 people contacted by email about the Delphi process, $47 \%$ of them ( $n=25$, including 1 from USA, 2 from British Columbia, 3 from Alberta, 1 from Saskatchewan, 3 from Manitoba, 5 from Ontario, 8 from Quebec, 2 from Newfoundland ) completed the round 1 Delphi survey and attended round 1 online meetings; $34 \%$ ( $n=18$, including 1 from USA, 1 from British Columbia, 2 from Alberta, 1 from Saskatchewan, 1 from Manitoba, 5 from Ontario, 5 from Quebec, 2 from Newfoundland) completed the round 2 Delphi survey and attended the round 2 online meeting. Average time to completion of the two surveys was 32.6 and 30.3 minutes. 


\section{Delphi process}

After round 2, strong agreement was achieved on 7 of 20 Evaluation Criteria, including: Answerability, Potential for translation, Effectiveness, Maximum potential impact on the burden, Equity, Relevance, and Fills key gap (Table 1). Seven additional criteria had more variance, and only the Likelihood of generating patents /lucrative products had a low median $=3(25-75 \%$ ile $=1-5)$.

Among 22 Research Priorities, four consensus priorities emerged as shown in Table 2. An additional 9 priorities had greater variance while none were low priority (median 1-3).

Fifteen of the 93 Measures /Constructs /Outcomes achieved high priority consensus. These included: Demographic/Environment/Context $(\mathrm{n}=4)$, Diet and Physical Activity $(\mathrm{n}=2)$, Formative and Process Measures $(\mathrm{n}=1)$, Psycho-social Constructs $(\mathrm{n}=1)$, Body Composition $(\mathrm{n}=3)$, Biological/Clinical History Measures $(n=4)$. None were considered of low relevance (median 1-3) as shown in Table 3. Nine statements were categorized as having weaker agreement. For example, gender (categorial) and various statements about physical activity fell into this group, as illustrated in Figures 2, 3, 4 and 5.

\section{Participants' Comments and Discussion}

Participants' diverse perspectives were evident throughout the process. Varied opinions were identified on diet and physical assessments, and approaches to assess cardiometabolic conditions, in line with issues of feasibility, measurement error, validity and cost based on participants' own research foci and experiences. Several participants emphasized the importance of involving relevant stakeholders (e.g., community partners, policymakers) at all stages of planned research proposal development.

Many participants were not familiar with the Delphi process, or with some of the measures and indicators. There were some missing data as some experts were uncomfortable rating measures that they were not familiar with. Terminology for the anchors (i.e., Relevant/Not Relevant) for the 9-point scales were problematic for a few participants. In discussion after the first survey, anchors for sections on Evaluation Criteria and Measures/Constructs were changed to Core/Not Core.

\section{Discussion}

The Delphi consensus process is an increasingly popular method to document the degree of agreement for complex topics. To our knowledge, this was the first attempt to use this method to establish research priorities and core measures and indicators specifically directed to lifestyle implementation studies for cardiometabolic conditions. Previous groups have focused on obesity research $(19,25)$. Participants reached consensus on four of 22 research priorities (Table 2), which indicated that most agree that efforts in our own countries should be directed to uptake/scale-up of current interventions in both the clinical and public health systems.

The addition of explicit consideration of the 20 evaluation criteria was prompted by prior work of the CHNRI in obtaining feedback on priorities from diverse experts (23). Despite our high-income setting, we 
felt we might have an analogous situation in which researchers from different disciplinary backgrounds were coming together, and the top-ranked criteria were aligned quite closely with the five CHNRI highpriority "standard" criteria: namely answerability, effectiveness, deliverability, maximum potential for disease burden reduction and the effect on equity. Our results differed from the CHNRI criteria in terms of interventions being deliverable, which likely reflects the greater focus on resource and infra-structure challenges in low- and middle-income countries. Our participants agreed that research with strong potential for translation was core. Our group also agreed that research that could fill a key gap was core, defined as "health research ideas that are more likely to fill the key gap in knowledge that is required for translation and/or implementation than the others". Generally, participants in this exercise had quite similar evaluation criteria.

With respect to measures, there was less consensus. Our interest in measures of cardiometabolic conditions differed from two other consensus processes for measuring obesity interventions (ADOPT and OBEDIS) $(19,25)$. The ADOPT measures were focused on explanatory research in weight loss $(21)$, while OBEDIS goals were closer to our own in recommending fewer core measures, but they were still oriented to weight loss treatment (19). Implementation variables, such as formative and process evaluation measures, were not included in either of the previous efforts. Reasons for variability in the scoring of some measures, such as gender and physical activity, warrants further investigation. Additional work on core measures is needed with a larger group, with additional opportunities to discuss strengths and limitations of various measures.

Strengths of this study included an inclusive and transparent process completed in a timely fashion using technology, allowing for both qualitative and quantitative feedback among volunteers in an emerging research network. The use of strict criteria for consensus made it possible to discern a small core set of research priorities for cardiometabolic conditions that have not been documented previously.

Although considered superior to typical committee approaches, in which one or more people may dominate decision-making, the Delphi approach represents the opinions of the participants involved (26). The participants were recruited to a voluntary research network. We worked on the basis of attracting interest and therefore no claims are made that the participants represent the diverse research community with an interest in the topic. Certainly, network participants are a convenience sample of the relevant research community. Wider promotion of the network and review of the findings to date are needed to ensure wider agreement with the priorities and measures currently identified.

Other challenges and limitations included the fact that only one-half of the group started the Delphi process and fewer still were able to complete both surveys. COVID19 shutdowns and changes in March 2020 affected the academic and personal lives of many in this group, which may have had an impact on participation. The implementation of the Quarantine Act by Canada was declared on March 24, 2020, after completion of the first survey (27). Future studies attempting a similar online approach to developing consensus must make additional efforts to keep participants engaged and oriented to the process and goals. Other approaches are likely needed, such as detailed discussion, to review strengths 
and limitations of various measures before any rating exercise. The further development of reporting guidelines for Delphi processes in different contexts is to be welcomed (16).

\section{Conclusions}

This is the first study to investigate research priorities, core measures and indicators for lifestyle implementation studies for cardiometabolic conditions, which will potentially be helpful to researchers interested in developing lifestyle-oriented research proposals to address cardiometabolic conditions. Through two rounds of Delphi process, we identified that current research priorities should focus on the implementation or scale up of existing interventions in both primary health care and community settings. While less consensus was achieved on evaluating measures/constructs/outcomes, the relevant concepts need to be re-examined with a larger participation group to distinguish the most essential measures from the rest of the list.

We also identified that virtual Delphi process can serve as an efficient methodology for generating research priories for lifestyle implementation studies. However, the relatively low participation rate indicates that modifications should be made to further engage participants. Detailed orientations on the Delphi process, and discussions on the listed statements should be offered to participants prior to the rating activities.

\section{Abbreviations}

- ADOPT: Accumulating Data to Optimally Predict Obesity Treatment

- BMI: Body mass index

- CHNRI: Child Health and Nutrition Research Initiative

- OBEDIS: OBEsity Diverse Interventions Sharing

- MRFIT: Multiple Risk Factor Intervention Trial

\section{Declarations}

- Ethics approval and consent to participate - Ethics approval not applicable

- Consent for publication - not applicable

- Availability of data and materials - The datasets used and/or analyzed during the current stay are available from $\mathrm{P}$ Brauer on reasonable request

- Competing interests - All authors declare that they have no competing interests

- Funding - ClHR Planning and Dissemination Grant. The funder had no role in the design of the study, data collection and analysis or interpretation of the data or writing the manuscript.

- Authors' contributions - Three researchers (PB, SD, RD) initiated the network, obtained funding and guided the process throughout. PB and YW created the online questionnaire, analyzed results and 
wrote initial drafts. AL helped initiate the network. AIC, DK, J-PD-C, JR, JH, MLP, RB, SVH and ZH are network members who participated in the process and reviewed and revised the paper. All authors read and approved the final manuscript.

- Acknowledgements - in kind support from Metabolic Syndrome Canada for online meetings (e.g., Zoom or similar) is gratefully acknowledged

\section{References}

1. GBD 2017 Risk Factor Collaborators. Global, regional, and national comparative risk assessment of 84 behavioural, environmental and occupational, and metabolic risks or clusters of risks for 195 countries and territories, 1990-2017: a systematic analysis for the Global Burden of Disease Study 2017. Lancet. 2018;392(10159):1923-94. Epub 2018/11/30. doi: 10.1016/s0140-6736(18)32225-6. PubMed PMID: 30496105; PMCID: PMC6227755.

2. Piché M-E, Poirier P, Lemieux I, Després J-P. Overview of Epidemiology and Contribution of Obesity and Body Fat Distribution to Cardiovascular Disease: An Update. Prog Cardiovasc Dis. 2018;61(2):103-13. doi: 10.1016/j.pcad.2018.06.004.

3. Statistics Canada. Metabolic syndrome in adults, 2012 to 2013. Ottawa: Statistics Canada; 2015. Available from: https://www150.statcan.gc.ca/n1/pub/82-625-x/2014001/article/14123-eng.htm. Accessed June 2019

4. Alberti KG, Eckel RH, Grundy SM, Zimmet PZ, Cleeman JI, Donato KA, et al., International Diabetes Federation Task Force on E, Prevention, Hational Heart L, Blood I, American Heart A, World Heart F, International Atherosclerosis S, International Association for the Study of O. Harmonizing the metabolic syndrome: a joint interim statement of the International Diabetes Federation Task Force on Epidemiology and Prevention; National Heart, Lung, and Blood Institute; American Heart Association; World Heart Federation; International Atherosclerosis Society; and International Association for the Study of Obesity. Circulation. 2009;120(16):1640-5. doi: 10.1161/CIRCULATIONAHA.109.192644. PubMed PMID: 19805654.

5. Tobe SW, Stone JA, Anderson T, Bacon S, Cheng AYY, Daskalopoulou SS, et al. Canadian Cardiovascular Harmonized National Guidelines Endeavour (C-CHANGE) guideline for the prevention and management of cardiovascular disease in primary care: 2018 update. CMAJ. 2018;190(40):E1192-e206. Epub 2018/10/12. doi: 10.1503/cmaj.180194. PubMed PMID: 30301743.

6. Hennessy DA, Tanuseputro P, Tuna M, Bennett C, Perez R, Shields M, et al. Population health impact of statin treatment in Canada. Health Rep. 2016;27(1):20-8. Epub 2016/01/21. PubMed PMID: 26788719.

7. Dolecek TA, Milas NC, Van Horn LV, Farrand ME, Gorder DD, Duchene AG, et al. A long-term nutrition intervention experience: lipid responses and dietary adherence patterns in the Multiple Risk Factor Intervention Trial. J Am Diet Assoc. 1986;86(6):752-8. Epub 1986/06/01. PubMed PMID: 3519737.

8. Teoh H, Despres JP, Dufour R, Fitchett DH, Goldin L, Goodman SG, et al. Identification and management of patients at elevated cardiometabolic risk in canadian primary care: how well are we 
doing? Can J Cardiol. 2013;29(8):960-8. Epub 2013/03/08. doi: 10.1016/j.cjca.2012.12.001. PubMed PMID: 23465284.

9. Arnett DK, Blumenthal RS, Albert MA, Buroker AB, Goldberger ZD, Hahn EJ, et al. 2019 ACC/AHA Guideline on the Primary Prevention of Cardiovascular Disease: Executive Summary: A Report of the American College of Cardiology/American Heart Association Task Force on Clinical Practice Guidelines. Circulation. 2019;140(11):e563-e95. Epub 2019/03/19. doi:

10.1161/cir.0000000000000677. PubMed PMID: 30879339.

10. National Institute for Health and Care Excellence. NICE Pathway: Cardiovascular Disease Prevention Overview 2020. Available from: https://pathways.nice.org.uk/pathways/cardiovascular-diseaseprevention/cardiovascular-disease-prevention-overview. Accessesd June 2020

11. Royal Australian College of General Practitioners. Chap. 8. Prevention of vascular and metabolic disease. Guidelines for preventive actitivies in general practice. 9th ed. East Melbourne: Royal Australian College of General Practitioners Ltd; 2018.

12. Pagoto $S$. The current state of lifestyle intervention implementation research: where do we go next? Transl Behav Med. 2011;1(3):401-5. Epub 2011/09/01. doi: 10.1007/s13142-011-0071-x. PubMed PMID: 24073065; PMCID: PMC3717623.

13. Visscher TL, Bell C, Gubbels JS, Huang TT, Bryant MJ, Peeters A, et al. Challenges in lifestyle and community interventions research; a call for innovation. BMC Obes. 2014;1:29. Epub 2014/01/01. doi: 10.1186/s40608-014-0029-x. PubMed PMID: 26217515; PMCID: PMC4511431.

14. Ackermann RT, O'Brien MJ. Evidence and Challenges for Translation and Population Impact of the Diabetes Prevention Program. Curr Diab Rep. 2020;20(3):9. Epub 2020/02/23. doi: 10.1007/s11892020-1293-4. PubMed PMID: 32080770.

15. Fitch K, Bernstein SJ, Aguilar MD, Burnand B, LaCalle JR. The RAND/UCLA appropriateness method user's manual. RAND CORP SANTA MONICA CA, 2001.

16. Junger S, Payne SA, Brine J, Radbruch L, Brearley SG. Guidance on Conducting and REporting DElphi Studies (CREDES) in palliative care: Recommendations based on a methodological systematic review. Palliat Med. 2017;31(8):684-706. Epub 2017/02/14. doi: 10.1177/0269216317690685. PubMed PMID: 28190381.

17. Priority setting for health research: lessons from developing countries. The Working Group on Priority Setting. Health Policy Plan. 2000;15(2):130-6. Epub 2000/06/03. doi: 10.1093/heapol/15.2.130. PubMed PMID: 10837035.

18. Viergever RF, Olifson S, Ghaffar A, Terry RF. A checklist for health research priority setting: nine common themes of good practice. Health Res Policy Syst. 2010;8:36. Epub 2010/12/17. doi: 10.1186/1478-4505-8-36. PubMed PMID: 21159163; PMCID: PMC3018439.

19. Alligier M, Barres R, Blaak EE, Boirie Y, Bouwman J, Brunault P, et al. OBEDIS Core Variables Project: European Expert Guidelines on a Minimal Core Set of Variables to Include in Randomized, Controlled Clinical Trials of Obesity Interventions. Obes Facts. 2020:1-28. Epub 2020/01/17. doi:

10.1159/000505342. PubMed PMID: 31945762. 
20. Hales S, Lesher-Trevino A, Ford N, Maher D, Ramsay A, Tran N. Reporting guidelines for implementation and operational research. Bull World Health Organ. 2016;94(1):58-64. Epub 2016/01/16. doi: 10.2471/blt.15.167585. PubMed PMID: 26769997; PMCID: PMC4709804.

21. Maclean PS, Rothman AJ, Nicastro HL, Czajkowski SM, Agurs-Collins T, Rice EL, et al. The Accumulating Data to Optimally Predict Obesity Treatment (ADOPT) Core Measures Project: Rationale and Approach. Obesity. 2018;26:S6-S15. doi: 10.1002/oby.22154.

22. Pinnock H, Barwick M, Carpenter CR, Eldridge S, Grandes G, Griffiths CJ, et al. Standards for Reporting Implementation Studies (StaRI) Statement. BMJ. 2017;356:i6795. Epub 2017/03/08. doi: 10.1136/bmj.i6795. PubMed PMID: 28264797; PMCID: PMC5421438.

23. Rudan I. Setting health research priorities using the CHNRI method: IV. Key conceptual advances. J Glob Health. 2016;6(1):010501. Epub 2016/07/16. doi: 10.7189/jogh-06-010501. PubMed PMID: 27418959; PMCID: PMC4938380.

24. Black RE. The legacy of the Child Health and Nutrition Research Initiative (CHNRI). J Glob Health. 2016;6(1):010101. Epub 2016/03/10. doi: 10.7189/jogh-06-010101. PubMed PMID: 26955468; PMCID: PMC4766789.

25. Rosenbaum M, Agurs-Collins T, Bray MS, Hall KD, Hopkins M et al. Accumulating Data to Optimally Predict Obesity Treatment (ADOPT): Recommendations from the Biological Domain. Obesity. 2018;26(S2):S25-S34. doi: doi:10.1002/oby.22156.

26. Keeney S, Hasson F, McKenna H. Consulting the oracle: ten lessons from using the Delphi technique in nursing research. J Adv Nurs. 2006;53(2):205-12. Epub 2006/01/21. doi: 10.1111/j.13652648.2006.03716.x. PubMed PMID: 16422719.

27. Public Health Agency of Canada. Coronvirus disease (COVID-19) Ottawa: Government of Canada; 2020. Available from: https://www.canada.ca/en/public-health/services/diseases/coronavirusdisease-covid-19.html. Accessed June 2020.

\section{Tables}

Table 1: Agreement with Evaluation Criteria ${ }^{3}$ 


\begin{tabular}{|c|c|}
\hline Strong Agreement Statement ${ }^{1}$ & Weaker Agreement Statement ${ }^{2}$ \\
\hline Answerability & Novelty \\
\hline Potential for translation & Deliverability \\
\hline Effectiveness & Sustainability \\
\hline Maximum potential impact on the burden & Ethical aspects \\
\hline Equity & Community involvement \\
\hline Relevance & Feasibility \\
\hline Fills key gap & Fundability \\
\hline
\end{tabular}

${ }^{1}$ All three indicators (median, $25^{\text {th }}$ percentile, and $75^{\text {th }}$ percentile) fall between $7-9$

$225^{\text {th }}-75^{\text {th }}$ percentile range falls outside $7-9$

${ }^{3}$ Criteria rated as Uncertain (did not meet the criteria for Strong or Weaker agreement) were:

Attractiveness (some health research ideas will be more likely to lead to publications in high-impact journals); Affordability (the implementation of knowledge generated through some health research ideas will not be affordable within the context); Public opinion; Cost; Alignment with political priorities; and Likelihood of generating patents/lucrative products.

Table 2: Agreement with Research Priorities ${ }^{3}$ 


\begin{tabular}{|ll|}
\hline Strong Agreement Statement ${ }^{1}$ & Weaker Agreement Statement $^{2}$ \\
\hline $\begin{array}{l}\text { Evaluating the efficacy and effectiveness of } \\
\text { interventions in place }\end{array}$ & Understanding risk factors \\
\hline $\begin{array}{l}\text { Improving existing interventions for sustainability } \\
\text { develop new capacities }\end{array}$ & $\begin{array}{l}\text { Measuring prevalence of exposure to risk } \\
\text { factors }\end{array}$ \\
\hline $\begin{array}{l}\text { Public health research to advance existing } \\
\text { knowledge to develop new capacities }\end{array}$ & $\begin{array}{l}\text { Measuring prevalence of coverage of } \\
\text { interventions in place }\end{array}$ \\
\hline $\begin{array}{l}\text { Improving existing interventions for } \\
\text { affordability }\end{array}$ \\
\hline $\begin{array}{l}\text { Improving existing interventions for } \\
\text { deliverability }\end{array}$ \\
\hline $\begin{array}{l}\text { Improving existing interventions for } \\
\text { acceptability }\end{array}$ \\
$\begin{array}{l}\text { Basic research to advance existing knowledge } \\
\text { to develop new capacities }\end{array}$ \\
$\begin{array}{l}\text { Clinical research to explore entirely novel ideas } \\
\text { Public health research to explore entirely novel } \\
\text { ideas }\end{array}$ \\
\hline
\end{tabular}

${ }^{1}$ All three indicators (median, $25^{\text {th }}$ percentile, and $75^{\text {th }}$ percentile) fall between $7-9$

$225^{\text {th }}-75^{\text {th }}$ percentile range falls outside $7-9$

${ }^{3}$ Priorities rated as Uncertain/equivocal (did not meet the criteria for strong or weaker agreement) were: Measuring the burden; Health policy analysis; Health system structure analysis; Financing/costs analysis; Human resources; Provision/infrastructure; Operations research; Responsiveness of recipients; and Basic research to explore entirely novel ideas.

\section{Table 3: Agreement with Measures/Constructs/Outcomes}




\section{Demographic/ Environment/Context}

\begin{tabular}{lll} 
Ethnicity & $\begin{array}{l}\text { Gender score } \\
\text { (categorical) }\end{array}$ & Gender score (continuous) \\
\hline Indigenous identity & Access to health care & Alcohol use \\
\hline Education & & Tobacco use \\
\hline Income & Language \\
\hline & Work status \\
& Marital status \\
\hline & Material Hardship \\
& Household size \\
\hline
\end{tabular}

\section{Diet and Physical Activity}

Usual dietary intake from 24 hour recalls or food frequency questionnaire

Diet quality
Physical activity record/diary

Self-report physical activity questionnaire

Physical activity, sedentary activity, sleep from actigraphy or accelerometer

Sedentary behaviours by a questionnaire

\section{Formative and Process Measures}

Intervention experience of participants in program

Type/extent of food processing as indicator of diet quality

Steps walked / day record

Costing of intervention

Intervention fidelity by activity reporting of interventionists

Intervention fidelity by observation /recording

Documentation of involvement of the public in developing the intervention 
Strong Agreement ${ }^{1}$

\section{Psycho-social Constructs}

Quality of Life questionnaire addressing self-care, usual activities, pain/discomfort and anxiety/ depression
Weaker Agreement ${ }^{2}$

Uncertain $^{3}$

General health or well- Medication adherence being

Self-efficacy

Perceived stress

Trait anxiety inventory

Depression

Intuitive Eating Scale

Three-Factor Eating Questionnaire

Self-weighing behaviour

State affect

Emotional eating

Binge eating

Trait food craving

Reward-related eating

Executive function

Delay discounting

Behavioural intention

Hedonic responses

Hunger and satiety

Personality: Big Five factors

\section{Body Composition and Energy Estimation}

Anatomic fat storage

Weight/height/BMl/waist

circumference

Energy Intake (overlap with diet measures)

\section{Biological/Clinical History Measures}

Hemoglobin A1c
N/A

Menopausal status
Expended energy

Energy expenditure-activity

Energy Expenditure - resting metabolic rate
Cardio-respiratory fitness at rest resting heart rate 


\section{Strong Agreement ${ }^{1}$}

Lipid profile

Co-morbidity score

Blood pressure
Weaker Agreement ${ }^{2}$

Uncertain $^{3}$

Cardio-respiratory fitness - walk test

VO2 max - indirect

Muscle strength from hand-grip strength

Glucose area under curve $2 \mathrm{~h}$ postprandial

Insulin, glucagon, HOMA-IR, HOMAB

Nutrient status

Fasting glucose (2 times)

Apo A; apo B

Cardiovascular disease risk score

Liver function (Aminotransferases $(\mathrm{U} / \mathrm{L})$, alkaline phosphatase (U/L), gamma-glutamyl transpeptidase (U/L)

Liver function - NFS and FIB4 fibrosis; platelet count; albumin

Fatty liver - ultrasound Inflammation (IL-6, TNF-alpha, CRP)

High sensitivity $C$ reactive protein

Heart electrical activity (ECG)

Self-report of sleep duration and timing

Sleep disorders (apnea)

Age of onset of obesity

Maximal and minimum weight after age 18

Variation in body weight in past 3 months

Previous attempts at weight loss and weight maintained after loss

Etiology - genetic heritage 


\begin{tabular}{|c|c|c|}
\hline \multirow[t]{6}{*}{ Strong Agreement ${ }^{1}$} & Weaker Agreement ${ }^{2}$ & Uncertain $^{3}$ \\
\hline & & $\begin{array}{l}\text { Parental weight history, including } \\
\text { maternal bariatric surgery }\end{array}$ \\
\hline & & Family history of diabetes \\
\hline & & $\begin{array}{l}\text { Hunger / satiety - Ghrelin, GLP-1, } \\
\text { PYY3-36 (panel) }\end{array}$ \\
\hline & & $\begin{array}{l}\text { Energy homeostasis - adipose } \\
\text { tissue-derived hormones } \\
\text { (adiponectin, leptin, amylin) }\end{array}$ \\
\hline & & $\begin{array}{l}\text { Thyroid hormones - (TSH, T4, fT4I } \\
\text { (panel) }\end{array}$ \\
\hline \multicolumn{3}{|c|}{ Social Environment and Context } \\
\hline & & $\begin{array}{l}\text { BMI of others in social network, } \\
\text { objective }\end{array}$ \\
\hline & & $\begin{array}{l}\text { Weight status of individuals in } \\
\text { social network, perceived }\end{array}$ \\
\hline & & Support from social network \\
\hline & & Perceived autonomy support \\
\hline
\end{tabular}

${ }^{1}$ All three indicators (median, $25^{\text {th }}$ percentile, and $75^{\text {th }}$ percentile) fall between $7-9$

$225^{\text {th }}$ percentile falls outside $7-9$ range

${ }^{3}$ All others.

\section{Figures}

$\begin{gathered}\text { Identify gaps \& } \\ \text { common } \\ \text { interests } \\ \text { opportunity } \\ \text { to interact and } \\ \text { review ongoing } \\ \text { work }\end{gathered}$
$\begin{gathered}\text { Create an } \\ \text { indicators for } \\ \text { studies }\end{gathered}$

\section{Figure 1}




$\begin{gathered}\text { Identify gaps \& } \\ \text { common } \\ \text { opportunity } \\ \text { interests } \\ \text { review ongoing } \\ \text { work }\end{gathered}$
interact and

\section{Figure 1}

Goals for Research Network

\begin{tabular}{|c|c|c|c|c|c|}
\hline 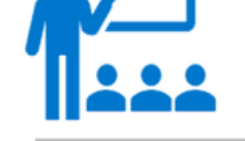 & $\begin{array}{c}\text { Identify gaps \& } \\
\text { common } \\
\text { interests }\end{array}$ & & $\begin{array}{c}\text { Identify } \\
\text { funding } \\
\text { opportunities }\end{array}$ & & $\begin{array}{l}\text { Publish \& } \\
\text { publicize } \\
\text { research }\end{array}$ \\
\hline $\begin{array}{c}\text { Create an } \\
\text { opportunity } \\
\text { to interact and } \\
\text { review ongoing } \\
\text { work }\end{array}$ & & $\begin{array}{c}\text { Delphi process for } \\
\text { common } \\
\text { outcome } \\
\text { indicators for } \\
\text { studies }\end{array}$ & & $\begin{array}{l}\text { Generate a } \\
\text { research agenda } \\
\text { of new } \\
\text { collaborations \& } \\
\text { funding } \\
\text { proposals }\end{array}$ & $\begin{array}{l}=4 \\
= \\
= \\
=\end{array}$ \\
\hline
\end{tabular}

Figure 1

Goals for Research Network

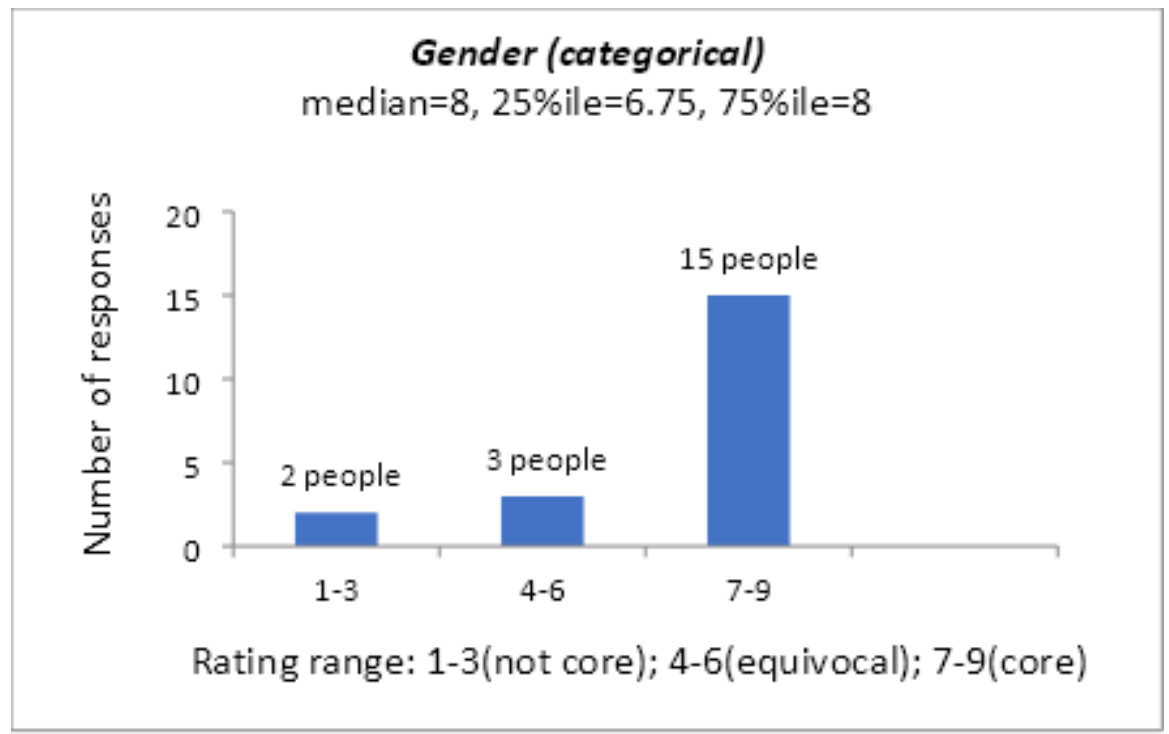

Figure 2

Rated importance of using Gender (categorical) as a measure/construct/outcome for cardiometabolic conditions 


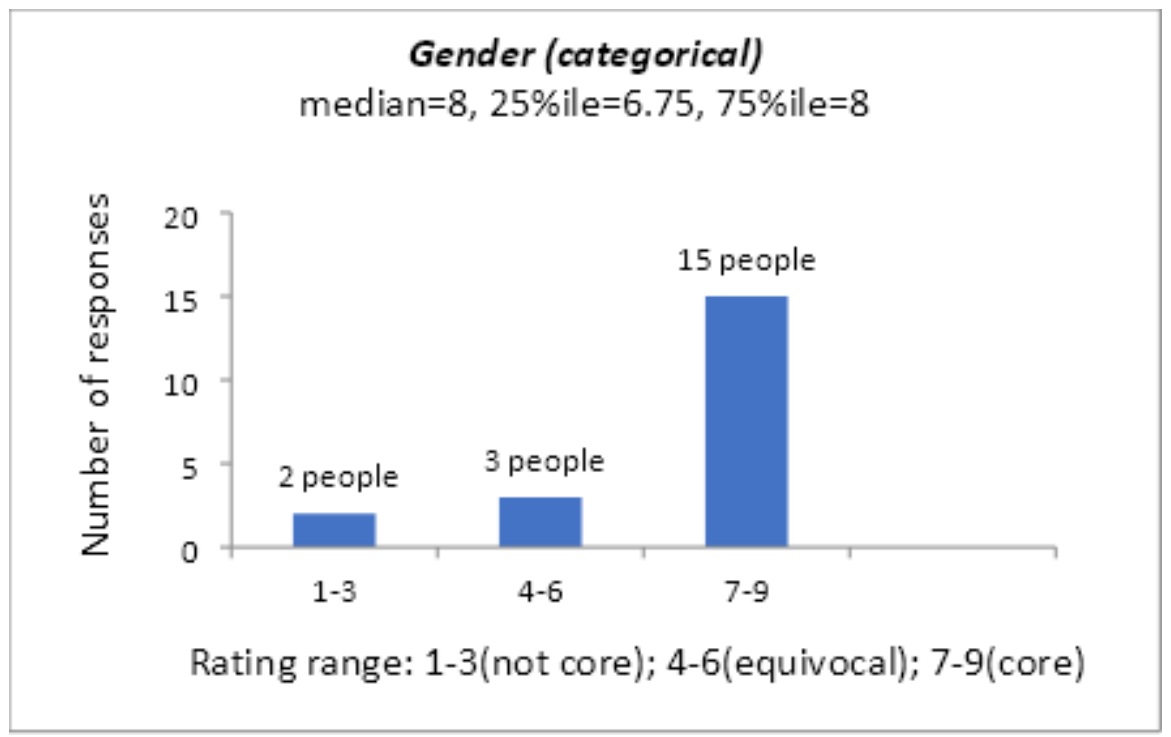

Figure 2

Rated importance of using Gender (categorical) as a measure/construct/outcome for cardiometabolic conditions

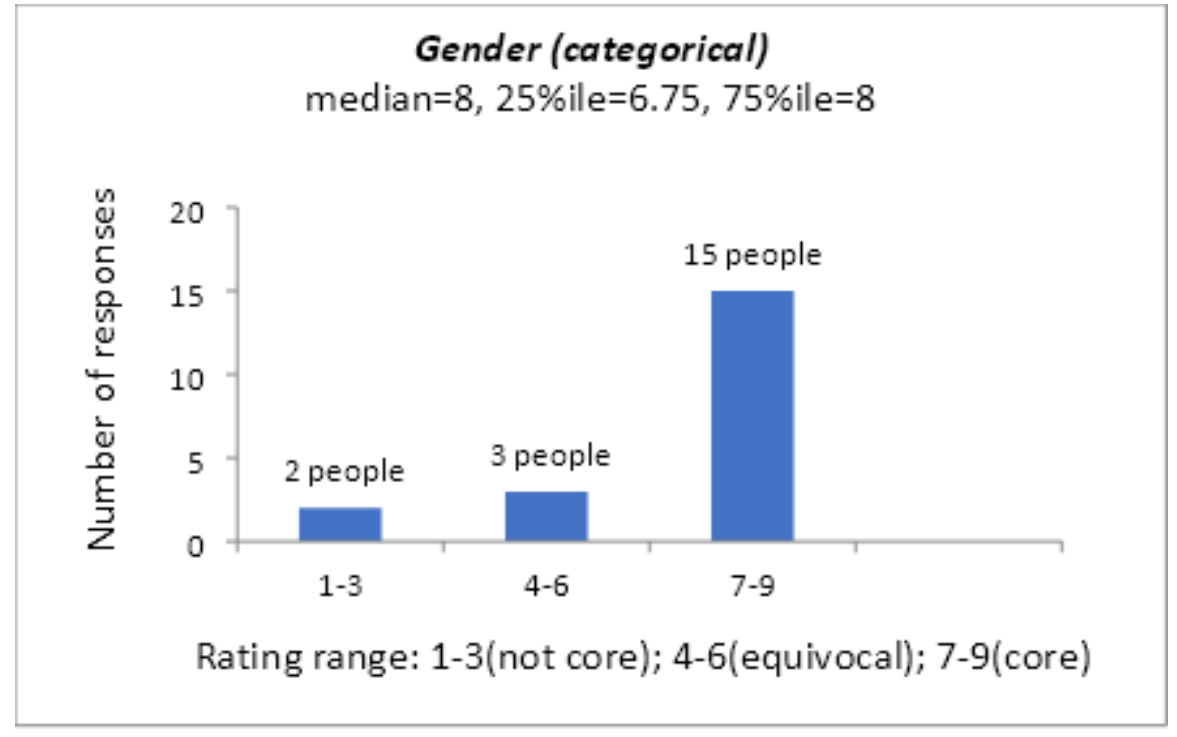

Figure 2

Rated importance of using Gender (categorical) as a measure/construct/outcome for cardiometabolic conditions 


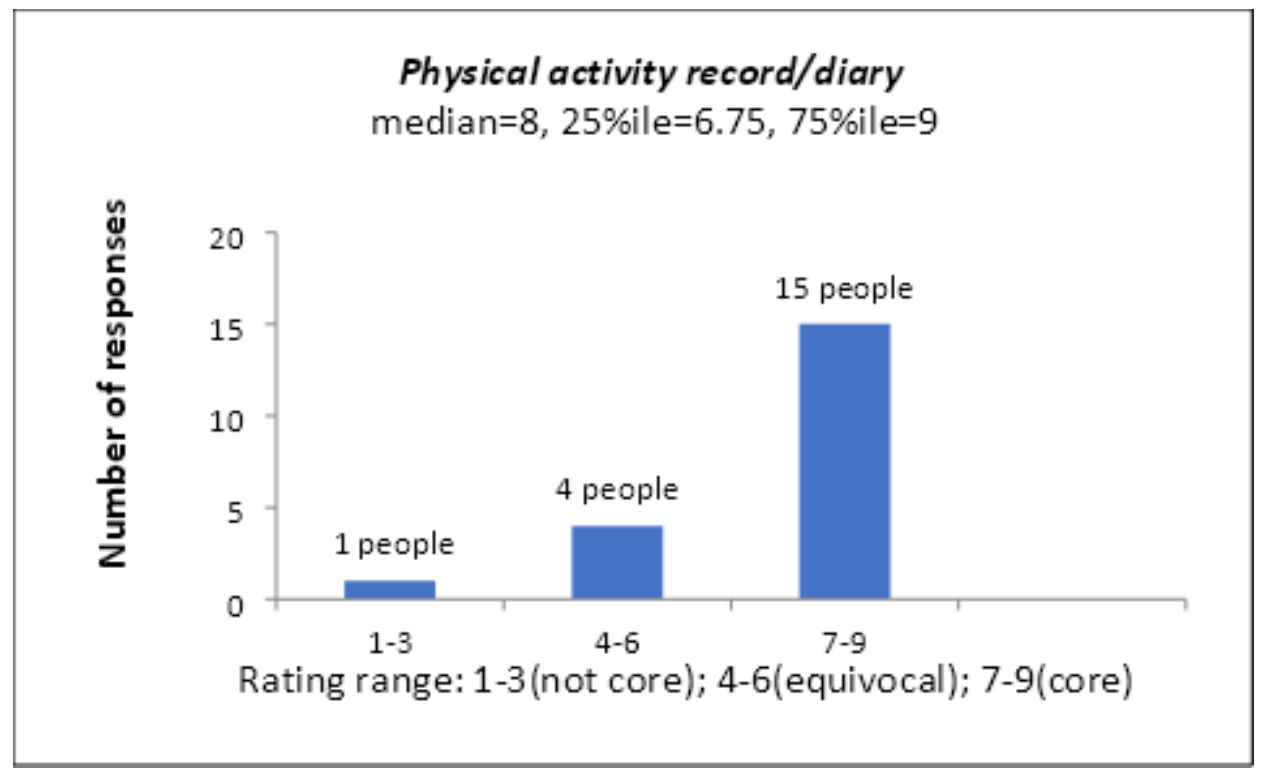

\section{Figure 3}

Rated importance of using Physical activity record/diary as a measure/construct/outcome for cardiometabolic conditions

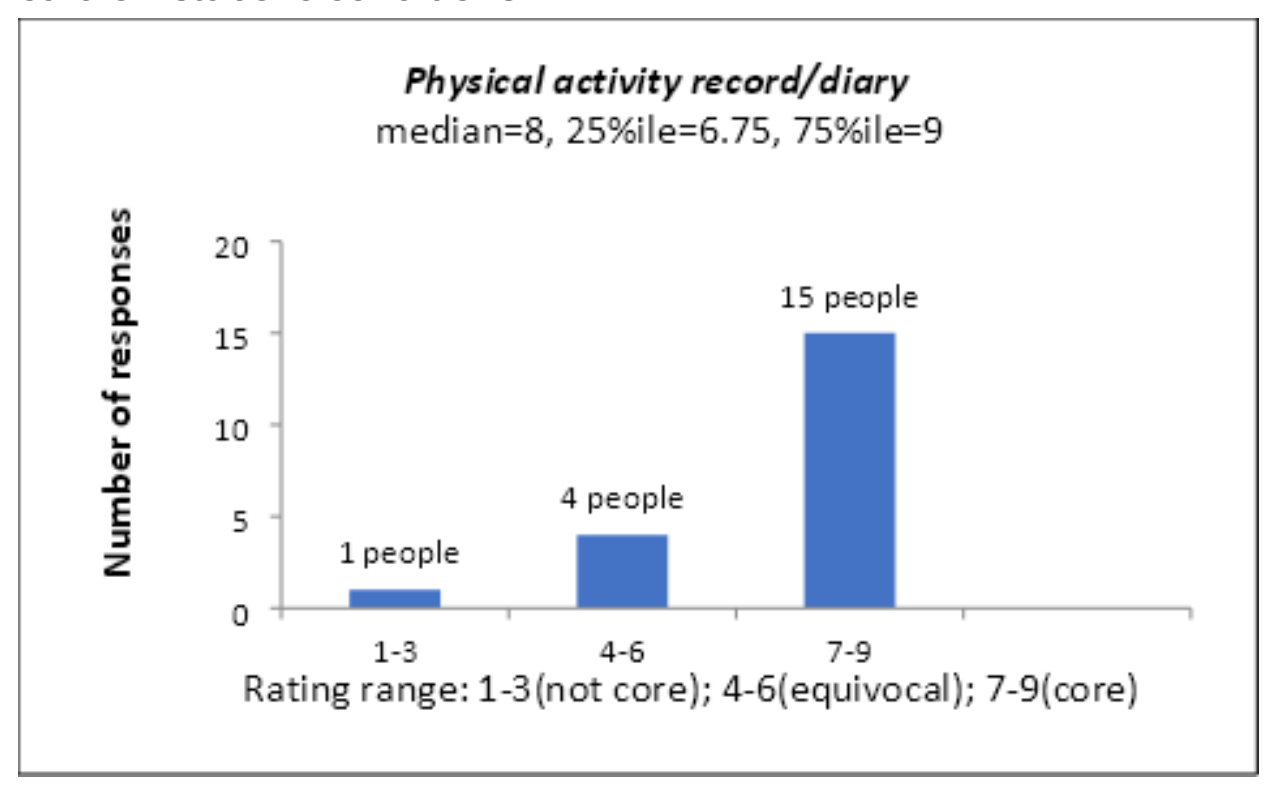

\section{Figure 3}

Rated importance of using Physical activity record/diary as a measure/construct/outcome for cardiometabolic conditions 


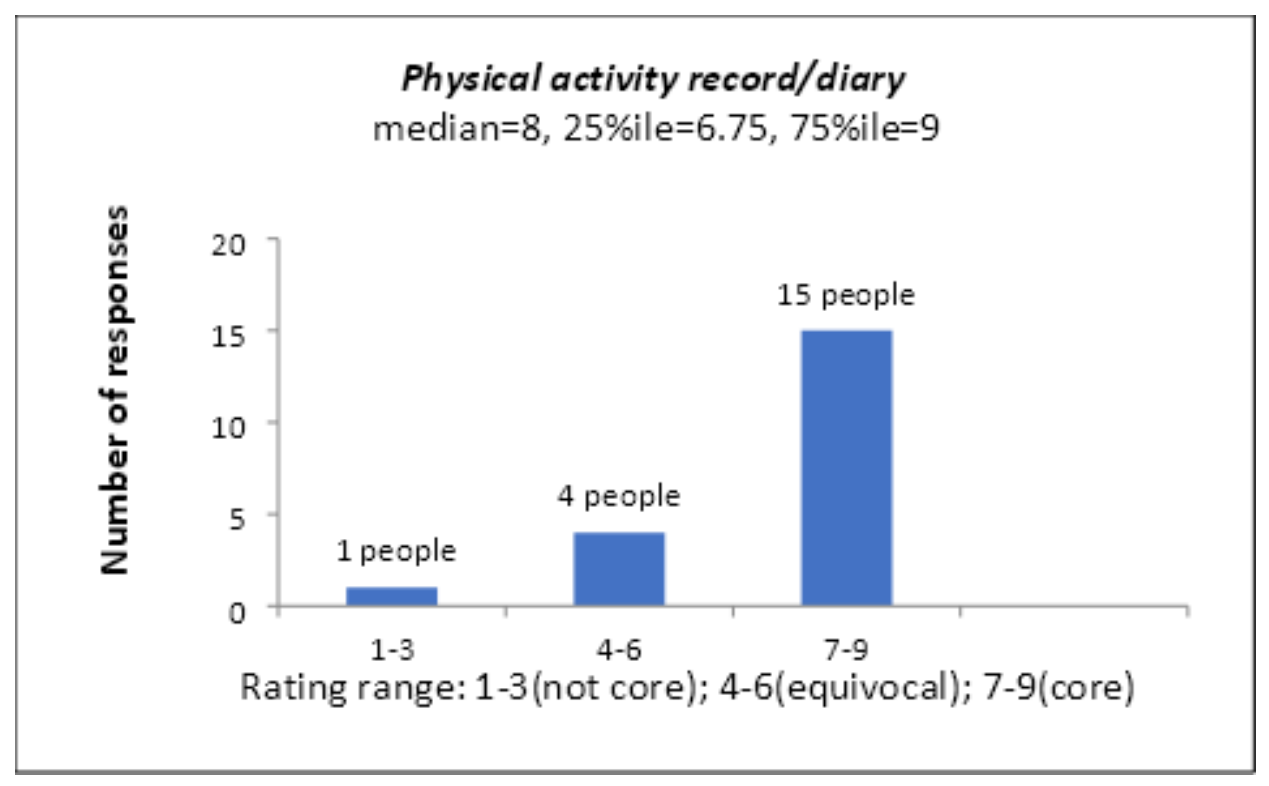

Figure 3

Rated importance of using Physical activity record/diary as a measure/construct/outcome for cardiometabolic conditions

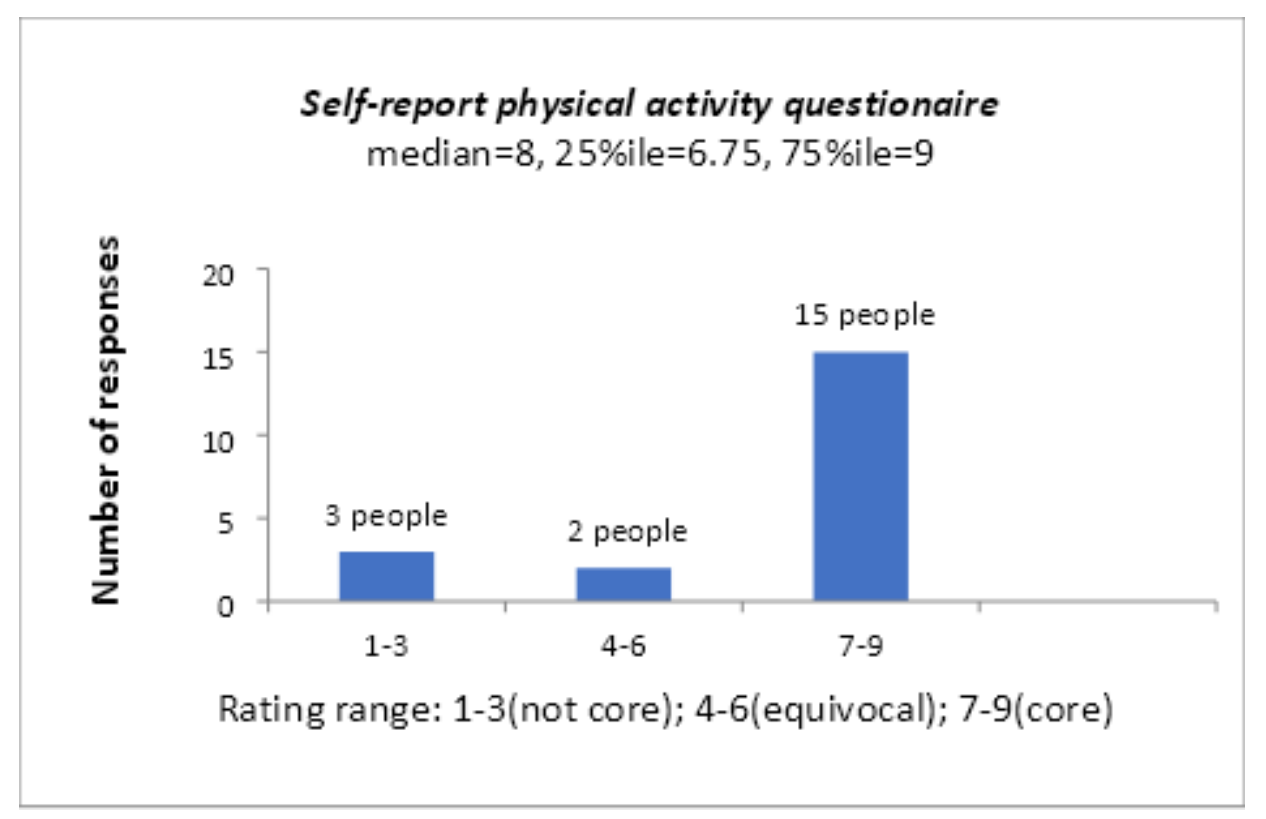

\section{Figure 4}

Rated importance of using Self-report physical activity questionaire as a measure/construct/outcome for cardiometabolic conditions 


\section{Self-report physical activity questionaire}

median $=8,25 \%$ ile $=6.75,75 \%$ ile $=9$

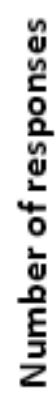

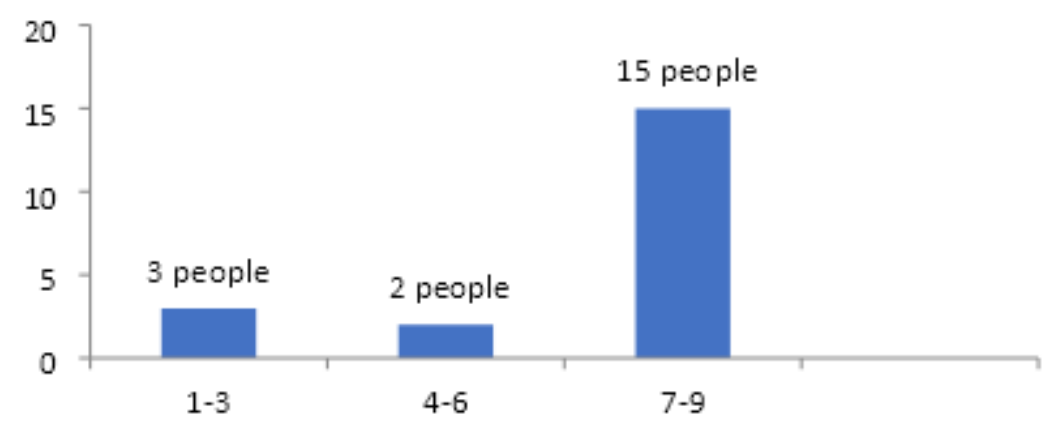

Rating range: $1-3$ (not core); 4-6(equivocal); 7-9(core)

\section{Figure 4}

Rated importance of using Self-report physical activity questionaire as a measure/construct/outcome for cardiometabolic conditions

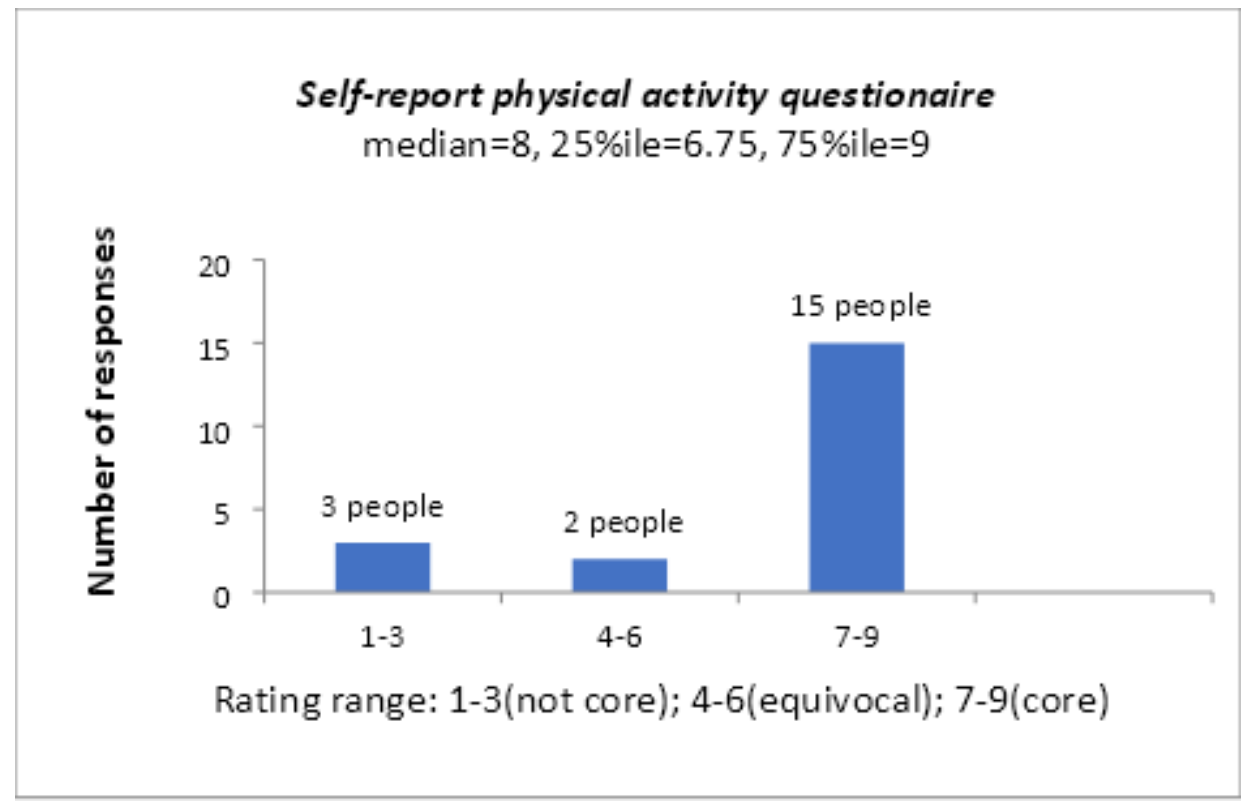

Figure 4

Rated importance of using Self-report physical activity questionaire as a measure/construct/outcome for cardiometabolic conditions 


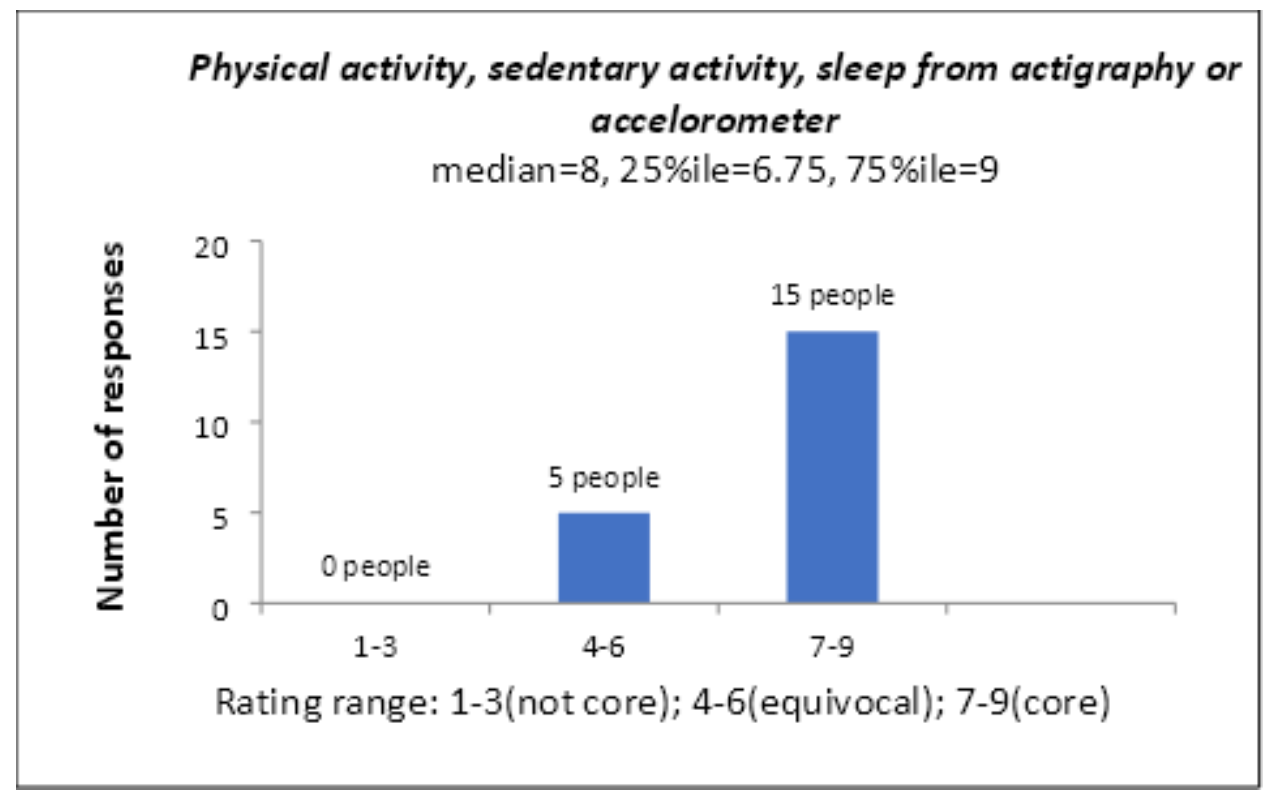

\section{Figure 5}

Rated importance of using Physical activity, sedentary activity, sleep from actigraphy or accelorometer as a measure/construct/outcome for cardiometabolic conditions

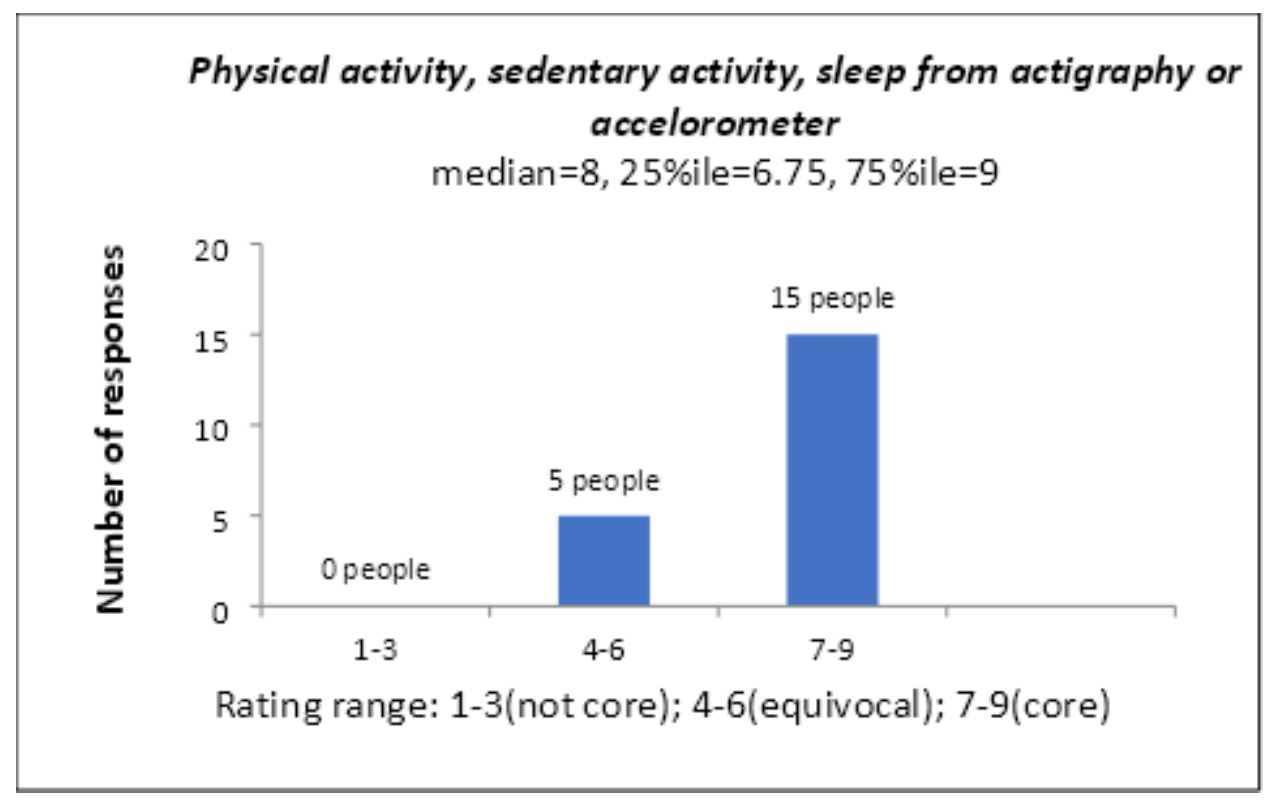

\section{Figure 5}

Rated importance of using Physical activity, sedentary activity, sleep from actigraphy or accelorometer as a measure/construct/outcome for cardiometabolic conditions 


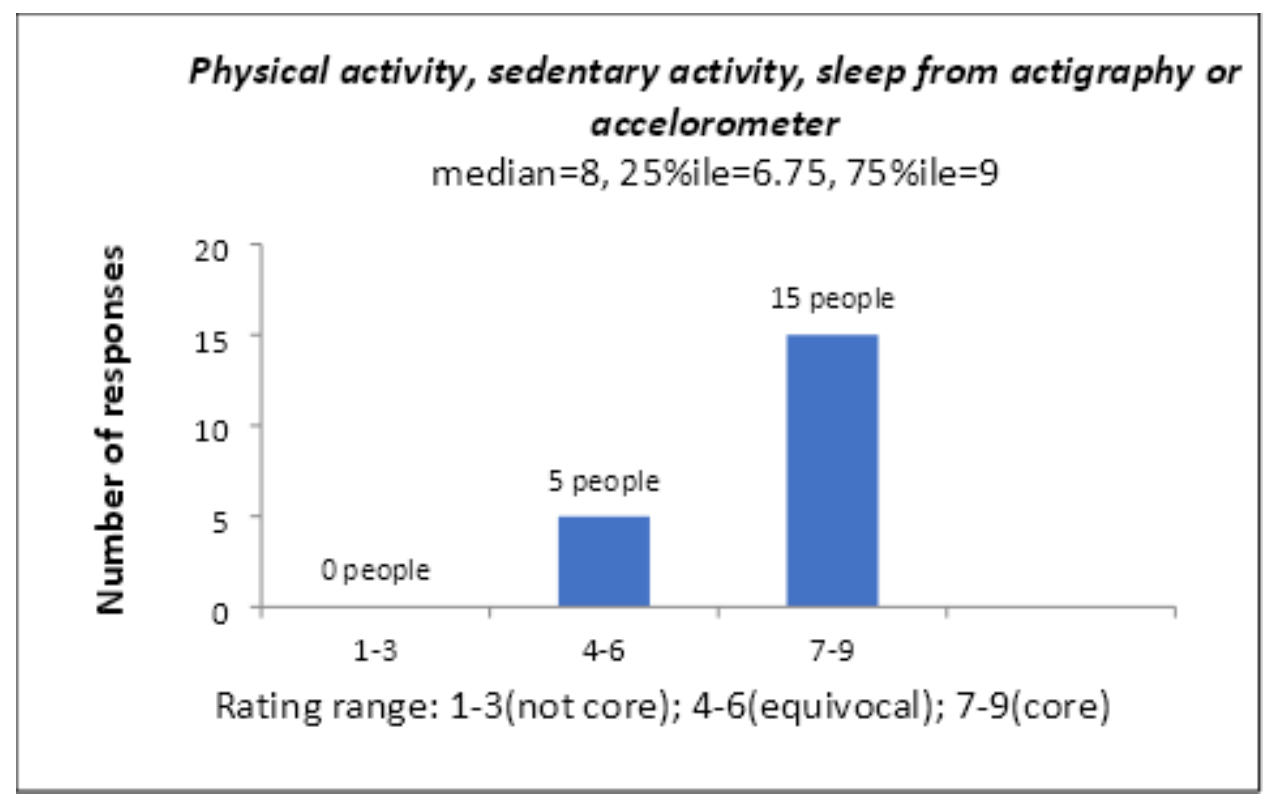

\section{Figure 5}

Rated importance of using Physical activity, sedentary activity, sleep from actigraphy or accelorometer as a measure/construct/outcome for cardiometabolic conditions

\section{Supplementary Files}

This is a list of supplementary files associated with this preprint. Click to download.

- AdditionalFile1.docx

- AdditionalFile1.docx

- AdditionalFile1.docx 